\title{
CLASSIFICAÇÃO DO ESTADO DE MATO GROSSO DO SUL SEGUNDO SISTEMA DE ZONAS DE VIDA DE HOLDRIDGE
}

\author{
IVASKO JÚNIOR, Severo - severoivasko@gmail.com \\ Universidade Federal do Paraná / UFPR
}

\begin{abstract}
MASTELLA, Alexandre Dal Forno - alexandremastella@gmail.com
Universidade Federal do Paraná / UFPR
\end{abstract}

TRES, Andressa - tres.andressa@gmail.com
Universidade Federal do Paraná / UFPR

TETTO, Alexandre França - tetto@ufpr.br
Universidade Federal do Paraná / UFPR

WENDLING, William Thomaz - wendling@ufpr.br Universidade Federal do Paraná / UFPR

SOARES, Ronaldo Viana - rvsoares@ufpr.br
Universidade Federal do Paraná / UFPR

RESUMO: O clima está relacionado com a vegetação, influenciando a sua distribuição, bem como a produtividade de atividades agrícolas e florestais. O objetivo deste trabalho foi classificar climaticamente os municípios do Mato Grosso do Sul, segundo o sistema de "zonas de vida" de Holdridge, e compará-lo com a classificação de Köppen e com o mapa de vegetação. Com os dados de temperatura e precipitação fornecidos por Alvares et al. (2013), foi possível calcular as biotemperaturas médias anuais dos 79 municípios que, em conjunto com a precipitação média anual, foram utilizadas no diagrama de Holdridge para determinação das zonas de vida. Os valores utilizados representam a média de, no mínimo, 25 anos de registros, obtidos entre 1950 e 1990, de 15 estações meteorológicas. Dados de altitude e latitude foram utilizados para determinação das regiões latitudinais e pisos altitudinais. A classificação climática foi realizada utilizando o programa FoxPro. Foram encontradas três zonas de vida para o estado de Mato Grosso do Sul: floresta úmida tropical premontana $(60,91 \%)$, floresta úmida subtropical basal $(38,99 \%)$ e transição entre floresta seca e floresta úmida subtropical basal $(0,1 \%)$, de modo que a classificação apresentou estreita relação com o gradiente altitudinal apresentado pelos municípios do estado. Conclui-se que as zonas de vida de Holdridge são apropriadas para classificar o clima de estado do Mato Grosso do Sul, tendo em vista que o sistema se mostrou satisfatório quando comparado à classificação de Köppen e à vegetação do estado.

PALAVRAS-CHAVE: Classificação climática; biotemperatura; fitogeografia.

\section{CLASSIFICATION OF MATO GROSSO DO SUL STATE ACCORDING TO THE HOLDRIDGE} LIFE ZONES SYSTEM

ABSTRACT: The weather condition is associated with local vegetation, which has a direct effect on forestry and agricultural activities. This study aimed to classify municipalities of Mato Grosso do Sul, Brazil, according to the living zones system proposed by Holdridge and compare these results with Köppen classification and vegetation map. The temperature and precipitation data provided by Alvares et al. (2013) allowed calculating the average annual biotemperatures of 79 municipalities. Both this data and the annual mean precipitation were used to classify the life zones of the Holdridge diagram. Those values represent the records obtained between 1950 and 1990 in 15 meteorological stations in the last 25 years. The altitude and latitude data were used to determine 
latitudinal and altitudinal levels. The climatic classification was performed using the FoxPro program. Three life zones were found for Mato Grosso do Sul State: tropical premontane moist forest $(60.91 \%)$, tropical moist forest $(38.99 \%)$ and transition between dry forest and subtropical moist forest $(0.1 \%)$. These results showed similar to the altitudinal gradient presented by the municipalities of the state. Thus, the Holdridge life zones are appropriate to classify the Mato Grosso do Sul climate conditions, once the system was satisfactory when compared to the classification of Köppen and the vegetation of the state.

KEYWORDS: Climatic classification; biotemperature; phytogeography.

\section{CLASIFICACIÓN DEL ESTADO DE MATO GROSSO DO SUL SEGUNDO SISTEMA DE ZONAS DE VIDA DE HOLDRIDGE}

RESUMEN: El clima está relacionado con la vegetación, influenciando su distribución, así como la productividad de actividades agrícolas y forestales. El objetivo de este trabajo fue clasificar climáticamente a los municipios de Mato Grosso do Sul, según el sistema de "zonas de vida" de Holdridge, y compararlo con la clasificación de Köppen y con el mapa de vegetación. Con los datos de temperatura y precipitación proporcionados por Alvares et al. (2013), fue posible calcular las biotemperaturas medias anuales de los 79 municipios que, junto con la precipitación media anual, se utilizaron en el diagrama de Holdridge para determinar las zonas de vida. Los valores utilizados representan la media de al menos 25 años de registros, obtenidos entre 1950 y 1990, de 15 estaciones meteorológicas. Los datos de altitud y latitud se utilizaron para determinar las regiones latitudinales y los pisos altitudinales. La clasificación climática fue realizada utilizando el programa FoxPro. Se encontraron tres zonas de vida para el estado de Mato Grosso del Sur: bosque húmedo tropical premontana $(60,91 \%)$, bosque húmedo subtropical basal $(38,99 \%)$ y transición entre bosque la sequía y el bosque húmedo subtropical basal $(0,1 \%)$, de modo que la clasificación presentó estrecha relación con el gradiente altitudinal presentado por los municipios del estado. Se concluye que las zonas de vida de Holdridge son apropiadas para clasificar el clima de estado de Mato Grosso del Sur, teniendo en cuenta que el sistema se mostró satisfactorio cuando comparado a la clasificación de Köppen ya la vegetación del estado.

PALABRAS CLAVE: Biotemperatura; tiempo; datos meteorológicos.

CLASSIFICATION DE L'ÉTAT DE MATO GROSSO DO SUL SECOND SYSTĖME DE ZONES DE VIE DE HOLDRIDGE

RÉSUMÉ: Le climat est lié à la végétation, influer sur la répartition et la productivité des activités agricoles et forestières. L'objectif de ce travail était climatiquement classifient les municipalités du Mato Grosso do Sul, selon le système des «zones de vie » de Holdridge, et le comparer avec la classification de Köppen et la carte de la végétation. Avec les données de température et de précipitation fournies par Alvares et al. (2013), il était possible de calculer la moyenne annuelle de 79 municipalités de biotemperaturas, ainsi que les précipitations annuelles moyennes, ont été utilisés dans le diagramme Holdridge pour déterminer les zones de vie. Les valeurs utilisées représentent la moyenne d'au moins 25 ans de relevés obtenus entre 1950 et 1990 sur 15 stations météorologiques. Les données d'altitude et de latitude ont été utilisées pour déterminer les niveaux latitudinal et altitudinal. La classification climatique a été réalisée à l'aide du programme FoxPro trois zones de vie ont été trouvées pour l'État du Mato Grosso do Sul $\therefore$ forêt tropicale premontana $(60,91 \%)$, la forêt subtropicale de base $(38,99 \%)$ et la transition entre la forêt la ligne de base séchée et forêt subtropicale $(0,1 \%)$, de sorte que la note a montré une relation étroite avec le altitudinal présenté par les municipalités. On en conclut que les zones de vie de Holdridge sont appropriées pour classer le climat de l'état du Mato Grosso do Sul, en considérant que le système était satisfaisant par rapport à la classification de Köppen et à la végétation de l'état.

MOT CLÉS: Biotemperature; climatologie; données météorologiques. 


\section{INTRODUÇÃO}

O clima é determinado pela interação entre os elementos meteorológicos e os fatores e variações macroclimáticas de um determinado local ou região (SOARES; BATISTA; TETTO, 2015), sendo caracterizado pelo estado médio da atmosfera em um determinado espaço de tempo (RODRIGUES et al., 2009). Além disso, o sistema climático da Terra é essencialmente não linear, pois está ligado a fatores intrínsecos e extrínsecos à própria atmosfera (TOMASONI, 2011).

De acordo com Molion (2012), o tempo e o clima interferem nas mais variadas atividades humanas, e, consequentemente, são algumas das maiores preocupações nos dias de hoje (MOREIRA et al., 2016). A relação entre o clima, a vegetação e a vida animal é observada há muito tempo, porém, devido à escassez de informações, não era possível realizar a classificação climática das regiões objeto de estudo. Então, no século XIX, os cientistas desenvolveram alguns sistemas de classificação, mas não obtiveram êxito, pois os dados meteorológicos eram limitados, não dando suporte a esses sistemas (SOARES; BATISTA; TETTO, 2015).

De maneira geral, as classificações climáticas têm por objetivo fornecer uma estrutura para a organização dos dados climáticos, cujas informações permitem a compreensão das variações do clima em todo o mundo (AYOADE, 2010). A classificação do clima pode ser realizada por meio da utilização de vários sistemas, sendo que os mais utilizados são as classificações de Köppen (1948), Thornthwaite (1948) e Holdridge (1967). Dentre estas, a classificação desenvolvida por Holdridge, também chamando de "zonas de vida" associa as formações vegetais com a precipitação anual, a taxa de evapotranspiração anual e a biotemperatura média anual (HINCAPIÉ; CAICEDO, 2013). De acordo com Holdridge (2000), a biotemperatura representa o intervalo de temperatura que permite $\mathrm{O}$ efetivo crescimento das plantas, compreendido de 0 a $30{ }^{\circ} \mathrm{C}$ (HOLDRIDGE, 2000).

Segundo Kanieski et al. (2012), a temperatura e a precipitação são os elementos do clima que mais influenciam o desenvolvimento da vegetação, já que esses fatores interferem diretamente na produtividade e crescimento das plantas. Desta forma, o uso adequado das classificações climáticas da vegetação facilita a realização do zoneamento agrícola ou florestal, além de ser uma ferramenta importante para a introdução de novas espécies, possibilitando inclusive um aumento da produtividade e qualidade dos produtos agroflorestais.

Do ponto de vista ecológico, a elaboração do zoneamento baseia-se no agrupamento das áreas que apresentam características ambientais semelhantes, com condições de clima, solos, relevo e vegetação homogêneos. Dentre essas variáveis, destaca-se o clima, pois este pode influenciar direta ou indiretamente os demais fatores (MILANO; BRASSIOLO; SOARES, 1987).

De acordo com Soares, Batista e Tetto (2015), além de serem facilmente mensuráveis, os dados de temperatura e precipitação são fundamentais para a realização da classificação climática, já que esses são os elementos que mais apresentam relação com o clima de uma região. 
Por ser um grande estado produtor agrícola, agropecuário e florestal, ter os biomas Cerrado e Pantanal dentro do seu território e ser mundialmente reconhecido por sua biodiversidade, o estado de Mato Grosso do Sul necessita de um adequado zoneamento climático para facilitar o planejamento dos produtores nas suas ocupações, minimizando os riscos e gerando oportunidade de melhor enquadramento ecológico para as atividades agrossilvipastoris. 0 objetivo principal deste trabalho foi classificar o clima dos municípios do estado de Mato Grosso do Sul segundo o sistema de zonas de vida de Holdridge, comparando-o com a classificação climática de Köppen e com a vegetação original.

\section{MATERIAL E MÉTODOS}

\section{CARACTERIZAÇÃO DA ÁREA DE ESTUDO}

O estado de Mato Grosso do Sul está localizado na região centro-oeste do Brasil, é o sexto maior estado do país, com área total de $357.145 \mathrm{~km}^{2}$, e está situado entre as coordenadas $17^{\circ} 09^{\prime} 59^{\prime \prime}$ e $18^{\circ} 02^{\prime} 30^{\prime \prime} \mathrm{S}$ e $50^{\circ} 55^{\prime} 22^{\prime \prime}$ e $58^{\circ}$ 10' 07" W (IBGE, 2015a).

O estado de Mato Grosso do Sul apresenta em toda a sua área os biomas Cerrado, Pantanal e Mata Atlântica (Figura 1), onde neles estão distribuídas as formações vegetais Cerrado (Savana), Floresta Estacional Semidecidual, Savana-estépica, além das áreas de formações pioneiras (IBGE, 2012).

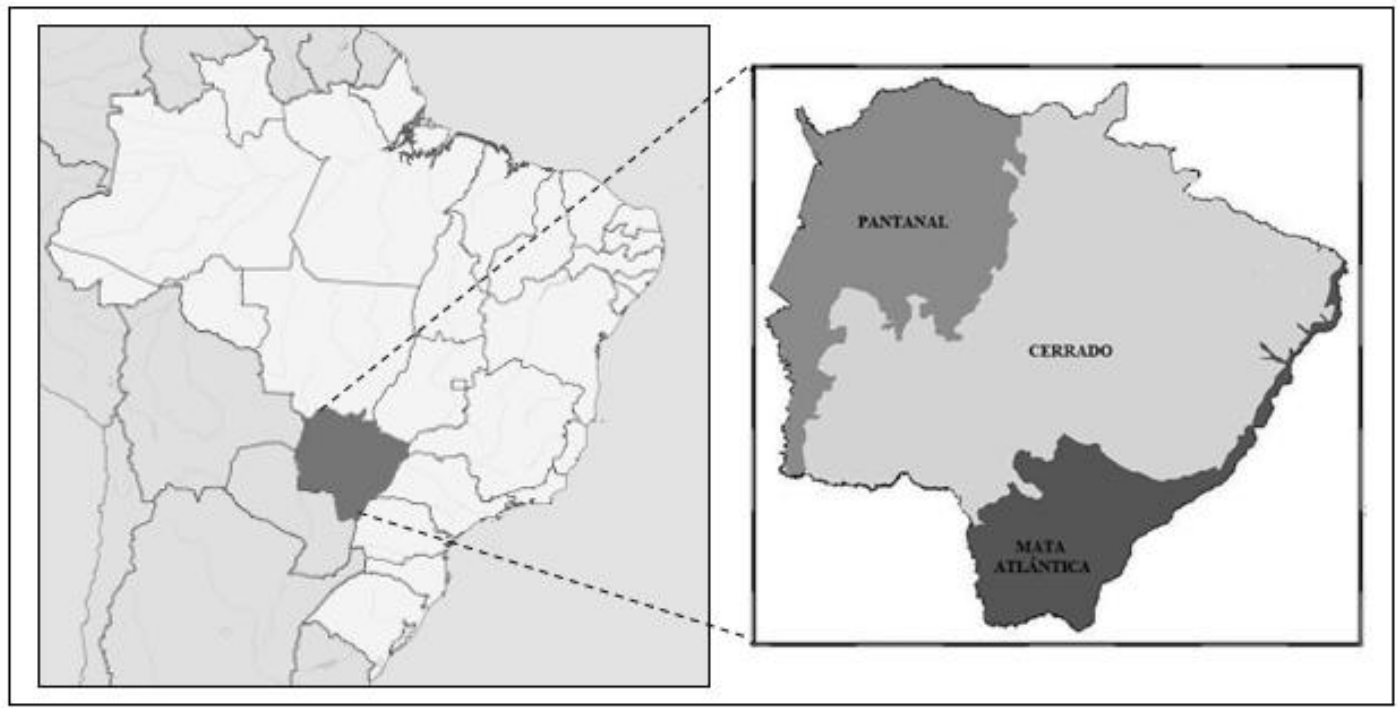

Figura 1- Mapa de localização e representação dos biomas do estado do Mato Grosso do Sul.

De acordo com Zavattini (2009), o estado do Mato Grosso do Sul apresenta baixos níveis de altitude nas regiões que correspondem com a área do pantanal sul-mato-grossense, localizado na faixa oeste do estado, ao passo que as demais regiões apresentam altitudes médias que oscilam de 300 a 600 $\mathrm{m}$, com exceção de uma pequena região no extremo norte do estado em que os picos de altitude ultrapassam esses níveis (Figura 2A). 
Quanto aos índices de precipitação, de acordo com Alvares et al. (2013), grande parte do estado possui clima tropical úmido, de estação seca no inverno, com totais pluviométricos oscilando de 1.000 a 2.000 mm (Figura 2B).

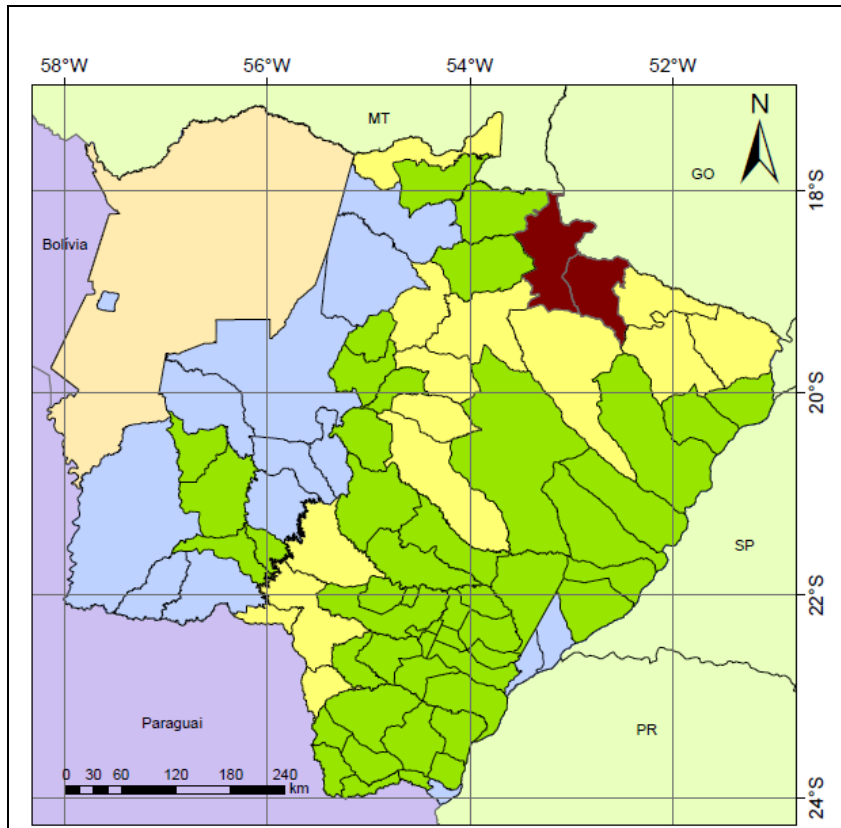

Legenda

Altitude (m)

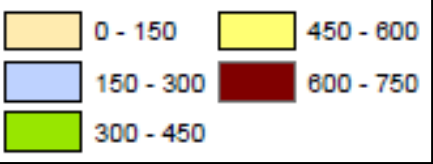

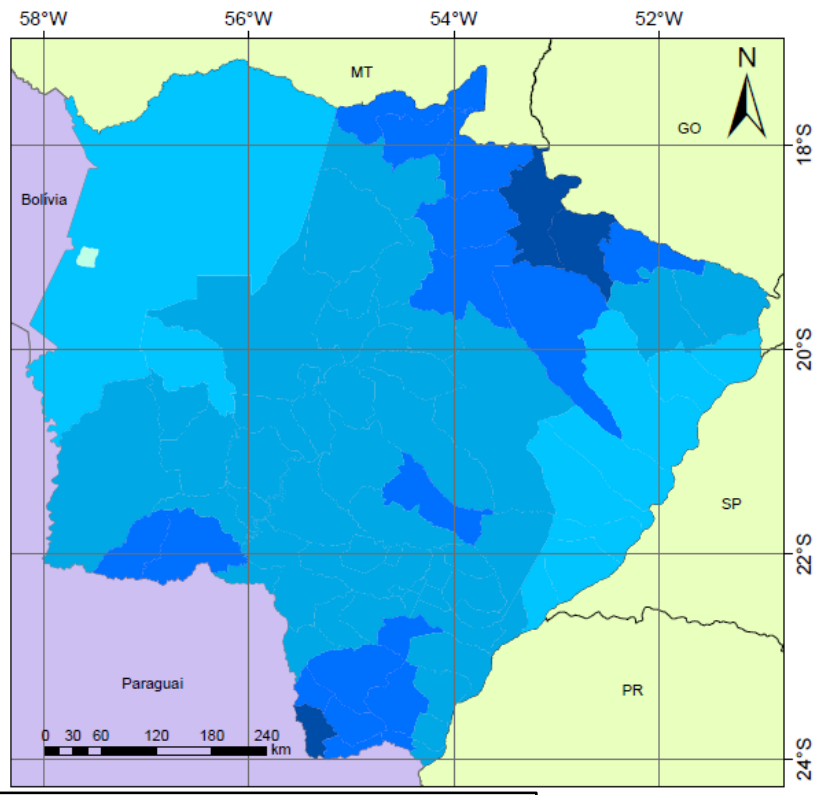

\section{Legenda \\ Precipitação média anual $(\mathrm{mm})$}

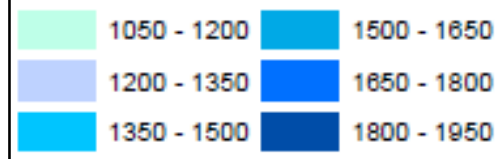

Figura 2 - Médias de altitude (Figura 2A) e precipitação anual (Figura 2B) do estado de Mato Grosso do Sul. Fonte: elaborado pelos autores (2018).

Além das médias mensais de temperatura e precipitação, a altitude e a precipitação média anual são variáveis essenciais para a classificação climática de um determinado local, de modo que estas variáveis influenciam significativamente na determinação das zonas de vida de Holdridge.

\section{COLETA DE DADOS}

Os dados climáticos foram obtidos por meio do banco de dados disponibilizado por Alvares et al. (2013), que fizeram a classificação de Köppen para o Brasil. A base de dados foi composta por mais de 25 anos de registros, durante os quais não houve nenhuma falha no registro de dados, entre os anos de 1950 a 1990. Em Mato Grosso do Sul, os dados foram extrapolados para os 79 municípios do estado, conforme metodologia também proposta por Alvares et al (2013).

De acordo com estes dados, as temperaturas médias mensais variaram de $18,7{ }^{\circ} \mathrm{C}$ para o mês de junho a $25,2{ }^{\circ} \mathrm{C}$ em janeiro. Enquanto isso, para a precipitação, pode-se verificar que o mês menos chuvoso foi julho $(47,8 \mathrm{~mm})$, enquanto o mês de maior precipitação foi dezembro (213,4 mm) (Figura 3). 


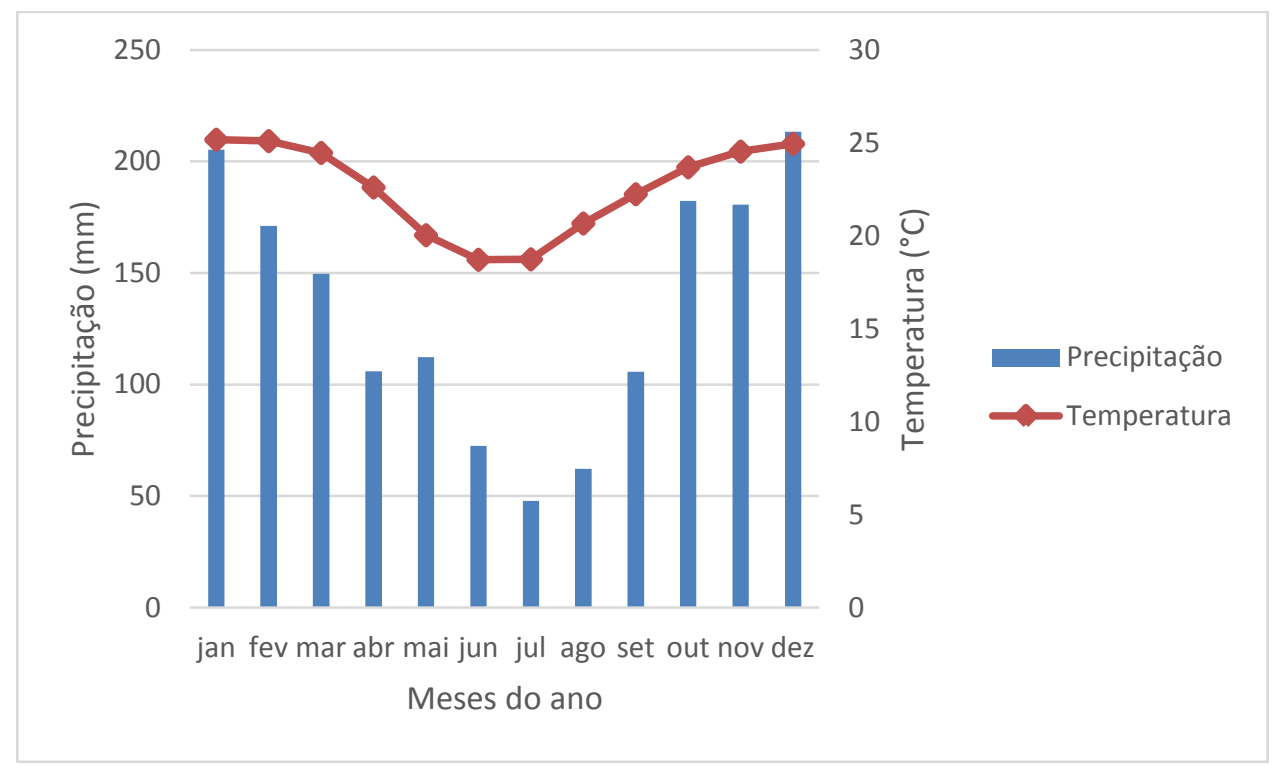

Figura 3 - Médias mensais de temperatura e precipitação de estado do Mato Grosso do Sul. Fonte: Alvares et al. (2013), elaborado pelos autores (2018).

A análise do comportamento desses dados meteorológicos permite verificar a distinção entre duas estações climáticas bem definidas no estado, sendo uma seca, presente no período de abril a setembro, e outra chuvosa, compreendendo os meses de outubro a março, esta última responsável por quase $70 \%$ do total anual de chuvas.

Esses dados corroboram com o estudo realizado por Zavattini (2009), onde o autor cita que as temperaturas da região do planalto sul-mato-grossense apresentam médias anuais elevadas e relativamente uniformes, enquanto as médias de precipitação apresentam variações mais acentuadas.

A dinâmica do comportamento das médias de temperatura e precipitação no estado podem ser explicados por uma série de fenômenos atmosféricos. Enquanto as baixas pressões, a elevada intensidade de radiação e as massas de ar são responsáveis pelas chuvas, as massas polares provenientes da Antártica são responsáveis pela queda de temperatura registrada de junho a agosto (ZAVATTINI, 2009).

\section{CLASSIFICAÇÃO DE HOLDRIDGE}

A classificação de Holdridge foi realizada segundo a metodologia proposta por Holdridge (2000), a qual utiliza o cálculo da biotemperatura e os valores de precipitação anual.

Para a determinação da biotemperatura, que compreende à faixa de temperatura em que ocorre o efetivo crescimento das plantas, foi considerado o intervalo entre 0 e $30^{\circ} \mathrm{C}$ (SOARES, BATISTA e TETTO, 2015). Assim, de acordo com Holdridge (2000), todas as temperaturas inferiores a $0^{\circ} \mathrm{C}$ foram descartadas, e as acima de $24^{\circ} \mathrm{C}$ foram corrigidas, com o objetivo de eliminar as temperaturas maiores que $30^{\circ} \mathrm{C}$ durante o mês, por meio da equação: 


$$
T \text { bio }=T-\left[\frac{3 l}{100}(T-24)^{2}\right]
$$

Onde:

$T$ bio = biotemperatura do mês, em ${ }^{\circ} \mathrm{C}$;

$T$ = temperatura média do mês, em ${ }^{\circ} \mathrm{C}$;

$l=$ latitude do lugar, em graus decimais.

Após a determinação das biotemperaturas mensais, estimou-se a biotemperatura média anual de cada município, por meio da soma de todas as biotemperaturas mensais com valores acima de $0^{\circ} \mathrm{C}$, dividindo-as por 12 (número de meses do ano).

De posse dos valores calculados de biotemperatura média anual e os dados de precipitação anual, foi possível determinar as zonas de vida por meio do diagrama de Holdridge (Figura 4).

Nesse diagrama, as linhas horizontais representam a biotemperatura média anual, e as linhas diagonais indicam a precipitação anual e a evapotranspiração potencial. A região do cruzamento dessas linhas indica a zona de vida de cada município, delimitadas pelos hexágonos.

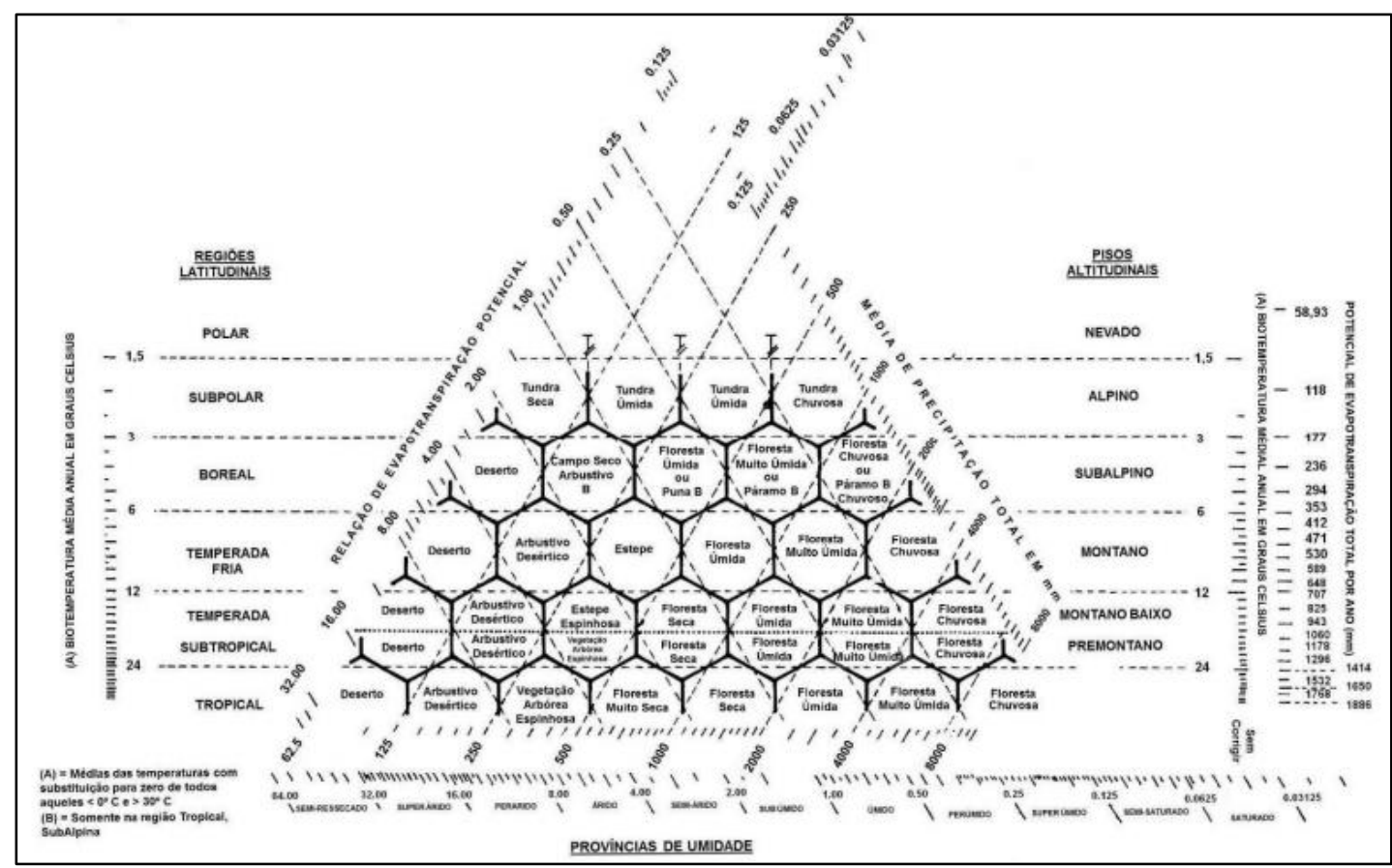

Figura 4 - Diagrama de classificação do sistema de Zonas de Vida de Holdridge. Fonte: Holdridge (2000), adaptado por Soares, Batista e Tetto (2015).

\section{ANÁLISE DOS DADOS}

Para verificar a afinidade da classificação climática das zonas de vida de Holdridge com outras metodologias de classificação do clima e vegetação, a mesma foi comparada com a classificação de Köppen (Figura 5), realizada por Alvares et al. (2013), e com o mapa de vegetação (Figura 6) do IBGE (2012). 


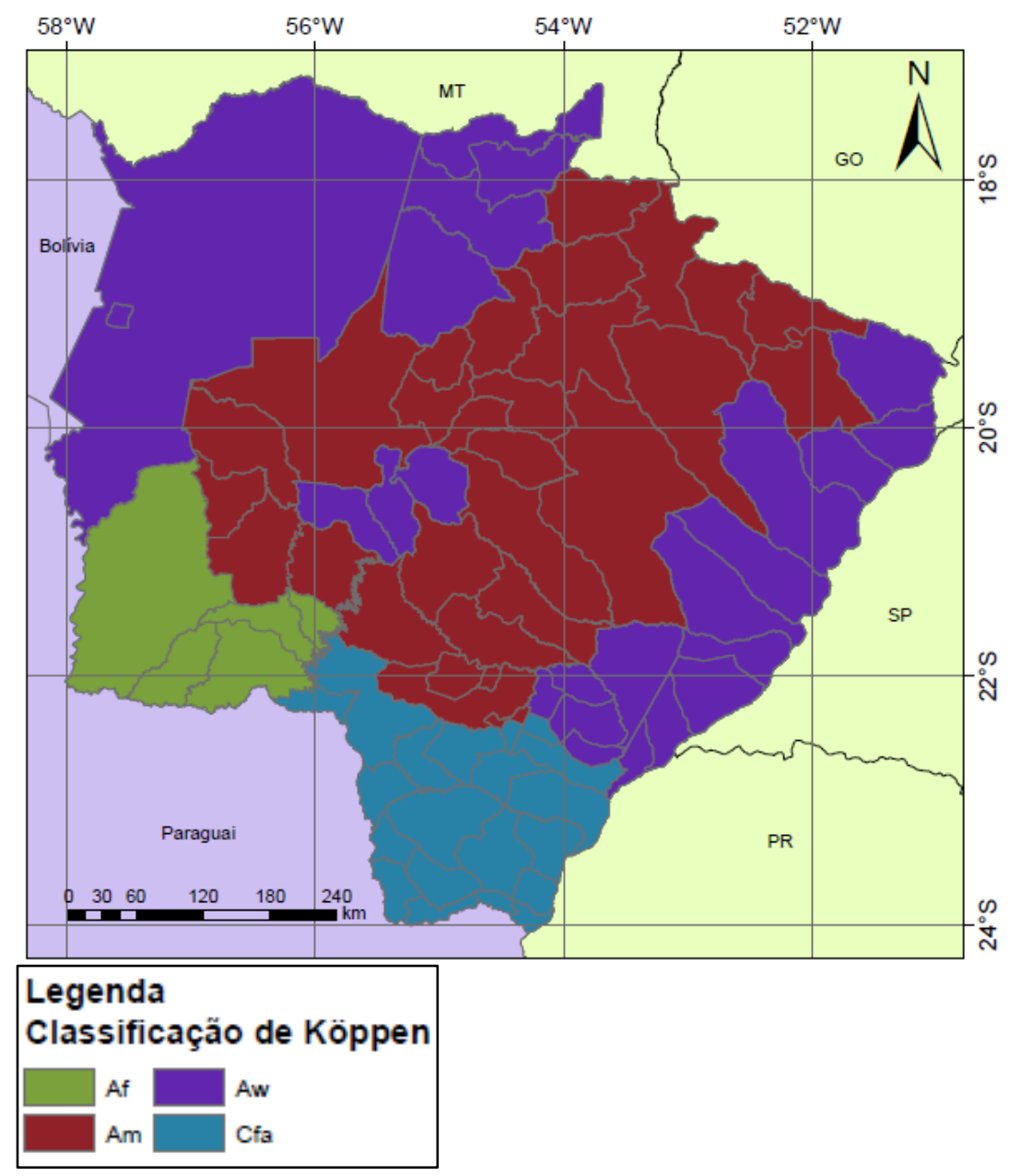

Figura 5 - Classificação climática de Köppen para o estado de Mato Grosso do Sul. Fonte: Alvares et al. (2013) elaborado pelos autores (2016).

Observa-se que o estado de Mato Grosso do Sul está dividido em quatro tipos de classificação: Am, definido como clima tropical de monção, Aw, clima tropical de savana, Cfa, clima temperado subtropical, e Af, também conhecido como clima equatorial. Segundo classificação de Köppen, o clima Am é caracterizado por apresentar temperatura média do mês mais frio superior a $18^{\circ} \mathrm{C}$ e estação seca de pequena duração. O clima Aw, por sua vez, apresenta estação chuvosa no verão (novembro a abril) e estação seca no inverno (maio a outubro), com temperatura média do mês mais frio superior a $18^{\circ} \mathrm{C} e$ precipitação do mês mais seco menor que 60mm (SOARES; BATISTA; TETTO, 2015). Por sua vez, o clima Cfa caracteriza-se por apresentar verões quentes, geadas pouco frequentes, chuvas mais concentradas no verão, mas sem estação seca definida, com temperatura média no mês mais frio inferior a $18^{\circ} \mathrm{C}$ e no mês mais quente superior a $22^{\circ} \mathrm{C}$ (IAPAR, 2016). O clima Af também não apresenta estação seca definida, com temperatura média do mês mais quente também superior a $18^{\circ} \mathrm{C}$, com precipitações mais concentradas de março a agosto, com $1.500 \mathrm{~mm}$ anuais e temperatura média nos meses mais quentes de 24 a $25^{\circ} \mathrm{C}$ (EMBRAPA, 2016). 


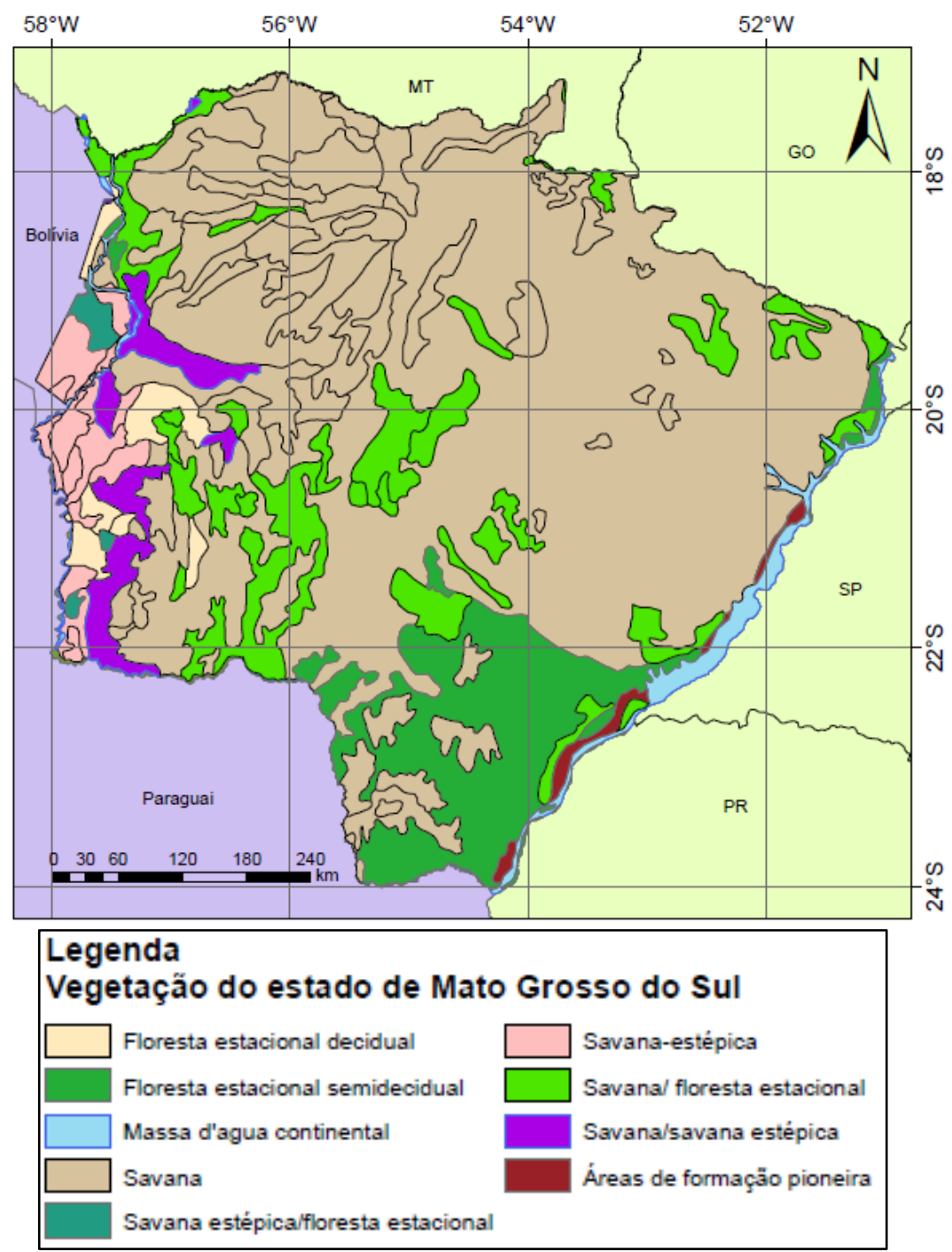

Figura 6 - Mapa de vegetação do estado de Mato Grosso do Sul. Fonte: IBGE (2012) elaborado pelos autores (2018).

Pode-se verificar pelo mapa da vegetação do estado de Mato Grosso do Sul uma divisão bem característica entre as formações vegetais mais secas na faixa norte, com predomínio da vegetação de savana, compreendida entre os biomas do cerrado e pantanal e a vegetação úmida, concentrada na região sul, com destaque da floresta estacional semidecidual, localizada sob uma área correspondente ao bioma Mata Atlântica. Tal distinção também pode ser observada analisando-se o mapa de classificação climática de Köppen, onde o clima tropical, típico de savana, predomina na faixa norte, enquanto o clima temperado subtropical influencia diretamente a formação de vegetação mais densa ao sul do estado.

Após determinar a área de cada tipologia em termos percentuais, foi calculada a área correspondente entre essas e as classificações climáticas de Köppen e Holdridge. 


\section{RESULTADOS E DISCUSSÃO}

\section{BIOTEMPERATURA}

Observa-se que a distribuição da biotemperatura é mais elevada na região norte do estado (Figura 7), na mesma área correspondente a vegetação mais seca de savana e do pantanal, com médias mensais de temperatura acima de $22^{\circ} \mathrm{C}$ e precipitação anual superior a $1.500 \mathrm{~mm}$.

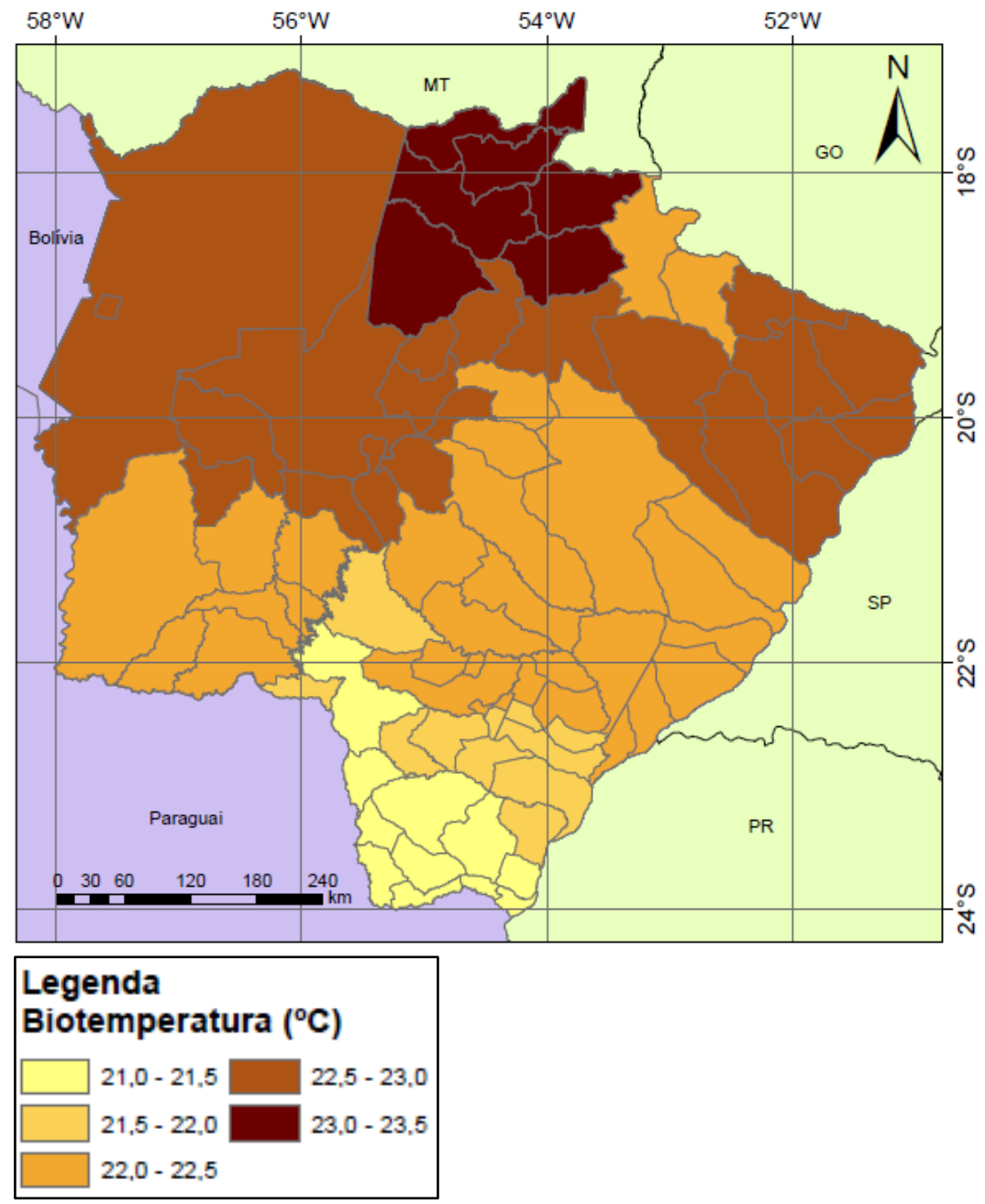

Figura 7 - Mapa de biotemperatura do estado de Mato Grosso do Sul. Fonte: elaborado pelos autores (2018).

\section{CLASSIFICAÇÃO DE HOLDRIDGE}

Segundo a classificação proposta por Holdridge, o estado de Mato Grosso do Sul possui três zonas de vida (Figura 8). 


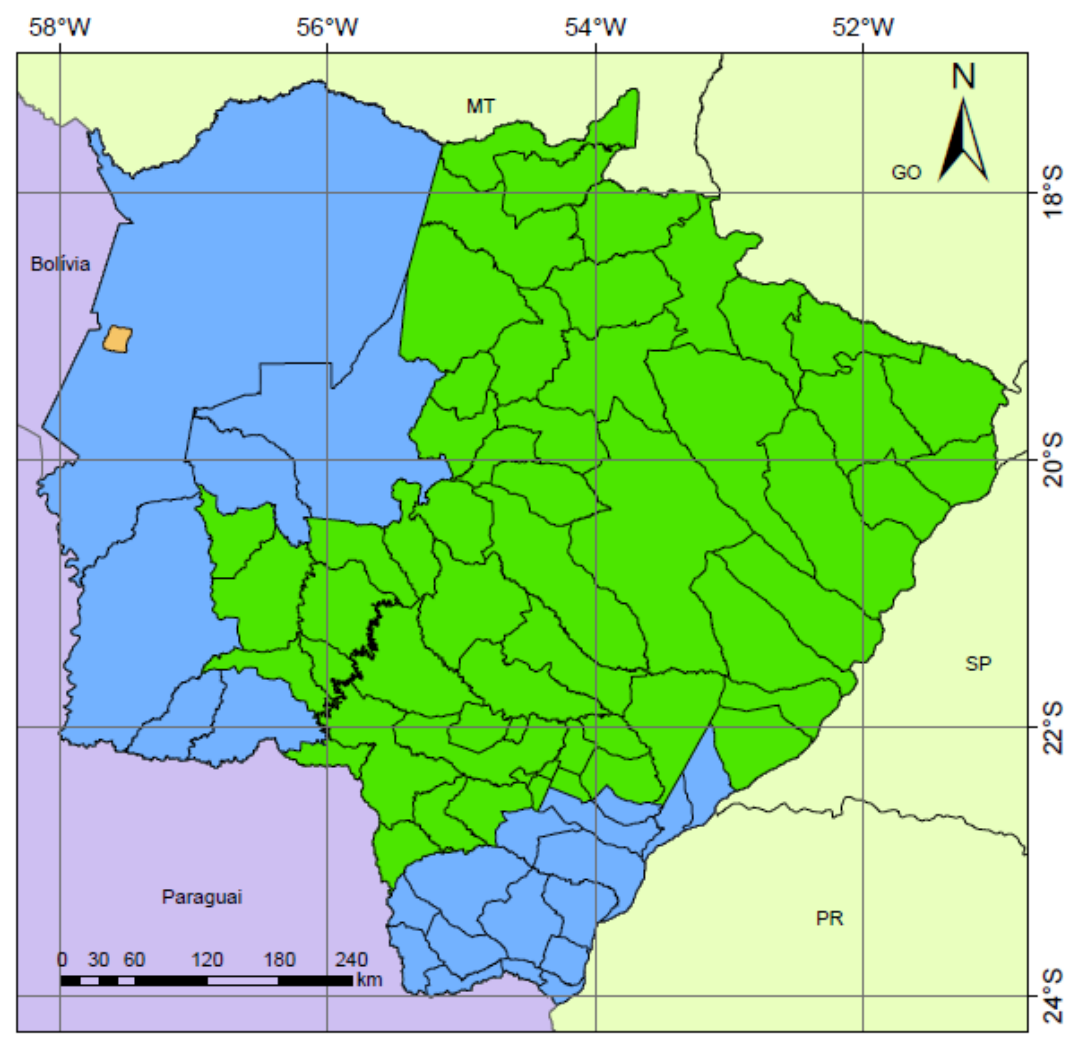

Figura 8 - Classificação de Holdridge para o estado de Mato Grosso do Sul. Fonte: elaborado pelos autores (2018).

Pode-se verificar que o estado do Mato Grosso do Sul divide-se em três zonas de vida, de acordo com a classificação de Holdridge, de modo que a maior proporção do estado se enquadra na zona de vida floresta úmida tropical premontana, localizada na porção centro-leste do estado, seguida pela floresta úmida subtropical basal, nas porções oeste, correspondente à área do pantanal sul-mato-grossense, e sul do estado, além de uma pequena área de transição entre a floresta úmida subtropical basal e a floresta seca, localizada na região noroeste do estado.

A área absoluta e relativa ocupada por cada zona de vida no estado podem ser observadas na Tabela 1.

Tabela 1 - Área e porcentagem correspondente a cada zona de vida segundo a classificação de Holdridge para o estado de Mato Grosso do Sul

\begin{tabular}{lcc}
\hline \multicolumn{1}{c}{ Classificação de Holdridge } & Área $\mathbf{( k m}^{\mathbf{2}} \mathbf{)}$ & $\mathbf{\%}$ \\
\hline Floresta seca/floresta úmida subtropical basal & 340,91 & 0,1 \\
Floresta úmida subtropical basal & $139.425,94$ & 38,99 \\
Floresta úmida tropical premontana & $217.796,45$ & 60,91 \\
\hline Total & $\mathbf{3 5 7 . 5 6 3 , 3 0}$ & $\mathbf{1 0 0}$ \\
\hline
\end{tabular}

Nota: Áreas calculadas com o software ArcGIS.

Com base na metodologia de Holdridge, o estado é totalmente coberto por zonas de vida florestais, sendo que 60,91\% dessa área é classificada como floresta úmida tropical premontana, 38,99\% corresponde à floresta úmida 
subtropical basal, além da área equivalente a 0,1\% caracterizada por ser uma área de transição entre essa floresta úmida e a floresta seca.

É possível verificar algumas similaridades entre a classificação climática de Holdridge e estudos que propuseram outras formas de classificação, como os estudos desenvolvidos por Nimer (1979) e Zavattini (2009), de modo que ambos indicam uma caracterização climática especifica para as regiões correspondentes ao pantanal sul mato-grossense, característico por representar uma zona de transição entre o clima seco e úmido subtropical na região.

Milano, Brassiolo e Soares (1987) realizaram a classificação de Holdridge para o estado do Paraná e encontraram sete zonas de vida: floresta úmida tropical premontana, úmida subtropical premontana, úmida temperada, muito úmida subtropical e áreas de transição entre a floresta úmida e muito úmida subtropical, floresta úmida e muito úmida temperada e floresta úmida temperada e seca temperada.

Para o estado de Santa Catarina, Nogueira, Kuniyoshi e Soares (1987) encontraram quatro zonas de vida, sendo estas: floresta úmida temperada, úmida subtropical, muito úmida temperada e transição da floresta muito úmida temperada para úmida temperada.

Tres et al. (2016) realizaram essa mesma classificação para o estado do Mato Grosso, e encontraram nove zonas de vida, sendo cinco áreas de transição entre floresta úmida e muito úmida tropical premontana, tropical basal, subtropical premontana, além da floresta úmida e seca subtropical premontana, sendo as outras quatro classificações a floresta úmida tropical premontana, úmida tropical basal, úmida subtropical premontana e úmida subtropical basal.

Nota-se que Paraná, Santa Catarina, Mato Grosso e Mato Grosso do Sul possuem áreas classificadas como floresta úmida. Não há, no estado de Santa Catarina, áreas de transição entre floresta úmida e seca, como nos outros três estados.

De acordo com a classificação de Holdridge realizada para o Brasil por Tres (2016), a classificação predominante para o estado, floresta úmida subtropical basal também se localiza em grande parte dos estados vizinhos, sendo característica de 244 de 246 municípios de Goiás, além de predominar na região sul de Mato Grosso e em grande parte dos estados de Minas Gerais, São Paulo e Paraná.

A exemplo da classificação encontrada em pequena parte do estado de Mato Grosso do Sul, áreas de transição entre floresta seca e floresta úmida subtropical basal são encontradas em dois municípios no norte de Goiás, em uma pequena faixa no sul da Bahia, no norte de Minas Gerais, além de ser característica de alguns municípios no sul do Espírito Santo e no norte do Rio de Janeiro.

Pode-se observar que apesar de duas zonas de vida do estado serem subtropicais e outra ser tropical, nos estados da região sul do Brasil aparecem as zonas de vida com regiões latitudinais temperadas, por estarem localizadas nas regiões mais frias do país.

O fato do estado apresentar três zonas de vida de características semelhantes, com uma pequena zona de transição mais seca, e outra extensa região mais úmida correspondente ao restante do estado pode ser explicado por 
meio do comportamento dos valores de biotemperatura e precipitação relativamente elevados dos municípios de Mato Grosso do Sul, cujas variáveis são as mais determinantes para a classificação de Holdridge.

Observou-se que, enquanto a biotemperatura média do município de Ladário $\left(22,7^{\circ} \mathrm{C}\right)$ tem proximidade com a média de todos os demais municípios do estado $\left(22,2^{\circ} \mathrm{C}\right)$, o que explica o fato das duas zonas de vida apresentarem característica subtropical basal, as médias de precipitação anual de Ladário são as menores do estado $(1.173 \mathrm{~mm})$ em comparação com a média dos demais municípios $(1.608 \mathrm{~mm})$, de modo que essa pequena região de transição apresenta uma condição de clima mais seco em comparação com o restante do estado. Da mesma forma, os municípios da região centro-leste do estado apresentam altitudes médias mais elevadas em relação às demais regiões, que são características responsáveis pelo fato do clima corresponder ao piso altitudinal premontano nesta porção do estado (MENGATTO, 2015).

Além de corresponder a 38,99\% da área do estado de Mato Grosso do Sul, Tres (2016) verificou, ao realizar a classificação climática de Holdridge para todo o território brasileiro, que a zona de vida floresta úmida subtropical basal predomina na região centro-oeste do país, ocupando $66,5 \%$ de toda a sua área. Mais precisamente, essa classificação climática cobre $99,4 \%$ do estado de Goiás e 66\% do território de Mato Grosso, especificamente na região sul do estado, na área de divisa entre os três estados do centro-oeste brasileiro.

\section{COMPARAÇÃO ENTRE AS CLASSIFICAÇÕES DE HOLDRIDGE E DE KÖPPEN} à Tabela 2 .

A comparação entre a classificação de Holdridge e de Köppen deu origem

Tabela 2 - Comparação entre a classificação de Köppen e as zonas de vida de Holdridge, em porcentagem, para o estado de Mato Grosso do Sul

\begin{tabular}{ccccccc}
\hline & \multicolumn{5}{c}{ Classificação de Holdridge } \\
\cline { 2 - 7 } $\begin{array}{c}\text { Classificação de } \\
\text { Köppen }\end{array}$ & $\begin{array}{c}\text { Floresta úmida } \\
\text { subtropical basal }\end{array}$ & $\begin{array}{c}\text { Floresta } \\
\text { seca/floresta úmida } \\
\text { subtropical basal }\end{array}$ & $\begin{array}{c}\text { Floresta úmida } \\
\text { tropical premontana }\end{array}$ \\
\cline { 2 - 7 } & Área $\left(\mathbf{k m}^{2}\right)$ & $\%$ & Área $\left(\mathbf{k m}^{2}\right)$ & $\%$ & Área $\left(\mathbf{k m}^{\mathbf{2}}\right)$ & $\mathbf{\%}$ \\
\hline Af & $25.799,11$ & 18,50 & 0,00 & 0,00 & $3.425,64$ & 1,57 \\
Am & $22.440,32$ & 16,09 & 0,00 & 0,00 & $122.550,82$ & 56,27 \\
Aw & $68.056,27$ & 48,82 & 340,91 & 100 & $78.817,07$ & 36,19 \\
Cfa & $23.130,24$ & 16,59 & 0,00 & 0,00 & $13.002,90$ & 5,97 \\
\hline Total & $\mathbf{1 3 9 . 4 2 5 , 9 4}$ & $\mathbf{1 0 0}$ & $\mathbf{3 4 0 , 9 1}$ & $\mathbf{1 0 0}$ & $\mathbf{2 1 7 . 7 9 6 , 4 5}$ & $\mathbf{1 0 0}$ \\
\hline
\end{tabular}

Nota: Áreas calculadas com o software ArcGIS.

Das três zonas de vida encontradas no Mato Grosso do Sul, a transição entre floresta seca e úmida subtropical basal têm correspondência de $100 \%$ com a classificação Aw de Köppen, enquanto a floresta úmida subtropical basal e a floresta úmida tropical premontana correspondem com as quatro diferentes classificações de Köppen presentes no estado. 
As maiores áreas de correspondência ocorrem entre a classificação Aw e pouco menos que a metade da área de floresta úmida subtropical basal. Enquanto isso, a área de floresta úmida tropical premontana corresponde em maior proporção com a classificação Am de Köppen.

Pode-se observar que o clima ligeiramente predominante é o do tipo Aw, característico do noroeste e sudeste do estado, seguido pelo clima Am, predominante na região central de Mato Grosso do Sul (Figura 3).

\section{COMPARAÇÃO ENTRE A CLASSIFICAÇÃO DE HOLDRIDGE E AS TIPOLOGIAS DE VEGETAÇÃO}

A comparação entre a classificação de Holdridge e a vegetação é apresentada na Tabela 3.

Tabela 3 - Comparação entre as zonas de vida de Holdridge e a vegetação, em porcentagem, para o estado de Mato Grosso do Sul.

\begin{tabular}{|c|c|c|c|c|c|c|}
\hline \multirow[t]{2}{*}{ Tipologia } & \multicolumn{2}{|c|}{$\begin{array}{l}\text { Floresta úmida } \\
\text { subtropical basal }\end{array}$} & \multicolumn{2}{|c|}{$\begin{array}{l}\text { Floresta seca/floresta } \\
\text { úmida subtropical basal }\end{array}$} & \multicolumn{2}{|c|}{$\begin{array}{l}\text { Floresta úmida } \\
\text { tropical } \\
\text { premontana }\end{array}$} \\
\hline & Área $\left(\mathrm{km}^{2}\right)$ & $\%$ & Área $\left(\mathrm{km}^{2}\right)$ & $\%$ & Área $\left(\mathrm{km}^{2}\right)$ & $\%$ \\
\hline $\begin{array}{l}\text { Fl. estacional } \\
\text { decidual }\end{array}$ & $6.101,91$ & 4,38 & 0,00 & 0,00 & 334,90 & 0,15 \\
\hline $\begin{array}{l}\text { Fl. estacional } \\
\text { semidecidual }\end{array}$ & $17.638,05$ & 12,65 & 0,00 & 0,00 & $19.256,73$ & 8,84 \\
\hline Savana & $78.805,56$ & 56,51 & 0,00 & 0,00 & $169.691,82$ & 77,91 \\
\hline $\begin{array}{l}\text { Savana estépica/fl. } \\
\text { estacional }\end{array}$ & $1.697,04$ & 1,22 & 189,39 & 55,56 & 0,00 & 0,00 \\
\hline Savana-estépica & $11.378,49$ & 8,16 & 151,52 & 44,44 & 0,00 & 0,00 \\
\hline $\begin{array}{l}\text { Savana/fl. } \\
\text { estacional }\end{array}$ & $11.851,44$ & 8,50 & 0,00 & 0,00 & $27.861,80$ & 12,79 \\
\hline $\begin{array}{l}\text { Savana/savana } \\
\text { estépica }\end{array}$ & $10.284,23$ & 7,38 & 0,00 & 0,00 & 55,82 & 0,04 \\
\hline $\begin{array}{l}\text { Áreas de formação } \\
\text { pioneira }\end{array}$ & $1.669,22$ & 1,20 & 0,00 & 0,00 & 595,38 & 0,27 \\
\hline Total & $139.425,94$ & 100 & 340,91 & 100 & 217.796,45 & 100 \\
\hline
\end{tabular}

Nota: Áreas calculadas com o software ArcGIS.

Pode-se observar que a floresta úmida subtropical basal correspondeu com todas as tipologias classificadas pelo IBGE, com destaque para a vegetação de savana. Além disso, essa tipologia também correspondeu em grande proporção com a zona de floresta úmida tropical premontana no estado, visto que essa tipologia é a que predomina no estado de Mato Grosso do Sul.

Enquanto isso, a zona de vida transição entre floresta seca e floresta úmida subtropical basal correspondeu com duas tipologias de vegetação predominantes de savana, o que explica o fato dessa região apresentar um clima mais seco, característico desse tipo de vegetação. A propósito, essas foram as únicas tipologias que não corresponderam com a zona de vida floresta úmida tropical premontana. 
Como a classificação de Holdridge mostrou-se homogênea para o estado, pode-se considerar que os valores de correspondência relativos são diretamente proporcionais à própria área representativa de cada tipologia estudada. Assim, a correspondência entre as classificações das zonas de vida floresta úmida subtropical basal e floresta úmida tropical premontana com os diferentes tipos de vegetação são maiores quanto maior for o predomínio de determinado tipo de vegetação no estado.

Foi possível verificar que a área classificada como zona de transição correspondeu com as tipologias de vegetação savana-estépica e savanaestépica/floresta estacional. Apesar disso, essas tipologias são representativas de uma pequena porção da vegetação do estado.

\section{CONCLUSÕES}

Foram definidas, pela classificação de Holdridge, três zonas de vida para o estado de Mato Grosso do Sul. Verificou-se que a floresta úmida subtropical basal apresentou quase $50 \%$ de correspondência com a classificação Aw de Köppen, característico da porção central do estado, além de corresponder totalmente à zona de vida caracterizada como sendo de transição entre esta e a floresta seca. Enquanto isso, o clima do tipo Am de Köppen predominou na área correspondente à zona de vida floresta úmida subtropical premontana, presente na porção centro-leste do estado.

Da mesma forma, foi possível constatar que dentro de uma mesma classificação de Holdridge podem existir diversas tipologias de vegetação, de modo que os gradientes altimétricos foram responsáveis pela diferenciação de toda a área do estado nas três classificações de Holdridge encontradas para o estado do Mato Grosso do Sul. Assim, o sistema de zonas de vida apresentou-se satisfatório para classificar o clima no estado, pois foi correspondente com a classificação de Köppen e com o mapa de vegetação.

\section{REFERÊNCIAS BIBLIOGRÁFICAS}

ALVARES, C. A.; STAPE, J. L.; SENTELHAS, P. C.; GONÇALVES, J. L. M.; SPAROVEK, G. Köppen's climate classification map for Brazil, Meteorologische Zeitschrift, v. 22, n. 6, p. $711-728,2013$.

AYOADE, J. O. Introdução à climatologia para os trópicos, $14^{a}$ ed. Rio de Janeiro: Bertrand Brasil, 2010.

EMBRAPA. Empresa Brasileira de Pesquisa Agropecuária. Espécies Arbóreas Brasileiras: Clima. 2016. Disponível em: http://www.cnpf.embrapa.br/pesquisa/efb/clima.htm. Acesso em 13 jun. 2018.

HINCAPIÉ, J. C. A.; CAICEDO, J. D. P. El cambio climático y la distribución espacial de las formaciones vegetales em Colombia, Colombia Forestal, Bogotá, v. 16, n. 2, p. $171-185,2013$.

HOLDRIDGE, L. R. Life zone ecology. San José: Tropical Science Center, 1967. $124 \mathrm{p}$.

HOLDRIDGE, L. R. Ecologia basada em zonas de vida. San José, Costa Rica: Instituto Interamericano de Cooperación para la Agricultura, 2000. 
IAPAR. Instituto Agronômico do Paraná. Cartas Climáticas do Paraná. Classificação Climática. 2018. Disponível em: http://www.iapar.br/pagina863.html. Acesso em 04 mai. 2018.

INSTITUTO BRASILEIRO DE GEOGRAFIA E ESTATÍSTICA (IBGE). Departamento de Recursos Naturais e Estudos Ambientais. Manual técnico da vegetação brasileira. 2a ed. Rio de Janeiro: IBGE, 2012.

$2015 a$.

- Latitude e longitude do estado de Mato Grosso do Sul. Brasil,

$2015 b$.

Área dos municípios do estado de Mato Grosso do Sul. Brasil,

KANIESKI, M. R.; SANTOS, T. L.; GRAF NETO, J.; SOUZA, T.; GALVÃO, F.; RODERJAN, C. V. Influência da precipitação e da temperatura no incremento diamétrico de espécies florestais aluviais em Araucária - PR. Floresta e Ambiente, v. 19, n. 1, p. 17 - 25, 2012.

KÖPPEN, W. Climatologia. Pánuco: Fondo de Cultura Económica, 1948. 487 p.

MENGATTO, A. P. R. Classificação climática de Holdridge para o estado de Mato Grosso. 42f. Trabalho de Conclusão de Curso (Graduação em Engenharia Florestal) - Universidade Federal do Paraná, Curitiba, 2015.

MILANO, M. S.; BRASSIOLO, M. M.; SOARES, R. V. Zoneamento ecológico experimental do estado do Paraná segundo o sistema de zonas da vida de Holdridge. Revista Floresta, Curitiba, v. 17, n. 1, p. 65 - 72, 1987.

MOLION, L. C. B. Apresentação. In: STEINKE, E. T. Climatologia fácil. São Paulo: Oficina de Textos, 2012.

MOREIRA, P. S. P.; DALLACORT, R.; GALVANIN, E. A. S.; NEVES, R. J.; CARVALHO, M. A. C.; BARBIERI, J. D. Ciclo diário de variáveis meteorológicas nos biomas do estado de Mato Grosso. Revista Brasileira de Climatologia, v. 17, p. 173 - 188, 2016.

NOGUEIRA, A. C.; KUNIYOSHI, Y. S.; SOARES, R. V. Zonas de vida para o estado de Santa Catarina segundo a classificação das formações vegetais de Holdridge. Floresta, Curitiba, v. 17, n. 1/2, p. 103 - 112, 1987.

RODRIGUES, R. A.; OLIVEIRA, G. A.; FARIA, A. L. L.; OLIVEIRA JUNIOR, A. Caracterização climática no entorno da usina hidroelétrica Serra do Facão (GO). In: TORRES, F. T. P.; DAGNINO, R. S.; OLIVEIRA JUNIOR, A. Contribuições geográficas. Ubá: Ed. Geographica, 2009. p. 521 - 542.

SOARES, R. V.; BATISTA, A. C.; TETTO, A. F. Meteorologia e climatologia florestal. Curitiba, 2015, 215 p.

THORNTHWAITE, C. W. An approach toward a rational classification of climate. Geographical Review, New York, v. 38, n. 1, p. 55 - 94, 1948.

TOMASONI, M. A. Mudanças globais: a problemática do ozônio e suas implicações. GeoTextos, Salvador, v. 7, n. 2, p. 141 - 178, 2011.

TRES, A. Classificação climática para o brasil segundo as zonas de vida de Holdridge. 89 f. Dissertação (Mestrado em Engenharia Florestal) - Universidade Federal do Paraná, Curitiba, 2016. 
TRES, A.; TETTO, A. F.; SOARES, R. V.; WENDLING, W. T.; MENGATTO, A. P. R. Classificação do estado de mato grosso segundo sistema de Zonas de vida de Holdridge. Enciclopedia Biosfera, v. 13, n. 23, p. 329 - 343, 2016.

ZAVATTINI, J. A. As chuvas e as massas de ar no estado de Mato Grosso do Sul: estudo geográfico com vista à regionalização climática [online]. São Paulo:

Editora UNESP; São Paulo: Cultura Acadêmica, 2009. 212 p 